\title{
Discussion on the Construction and Reform of Industrial Robot Specialty
}

\author{
Yi Jiangang*, Xu Pin, Ju Siwei, Wei Pengfei \\ School of Electromechanical and Architectural Engineering \\ Jianghan University \\ Wuhan City, China \\ yjg_wh@yeah.net
}

\begin{abstract}
Aiming at the new requirements of undergraduate education for national and enterprise development, the construction of industrial robot specialty for undergraduate education is proposed in the undergraduate course. Starting from market requirements, the post composition of industrial robot enterprises is analyzed. Based on it, the industrial robot professional training objectives are set up and the new course system which is mainly composed of innovation and practice is built. The experimental teaching system of the industrial robot specialty is reconstructed by integrating the school laboratories and enterprise equipment resources in order to provide new ideas to the undergraduate education of industrial robot specialty.
\end{abstract}

Keywords-specialty construction; Talent training; undergraduate education; Industrial robot

\section{INTRODUCTION}

Industrial robot is a highly integrated field, which represents the high-tech development level of a country [1]. Meanwhile, it is also a multi-disciplinary, highly integrated subject. The latest achievements in the fields of applied mathematics, mechanics, electronics, computers, automatic control, sensing technology, communications and artificial intelligence are combined in it [2]. Creating industrial robot specialty helps generating the students' potential, improving students' design ability, innovation ability, practical ability and cross-professional comprehensive application ability, which improves the scientific quality of students in university undergraduate education [3-6].

In 2014, Chairman $\mathrm{Xi}$ underlined that the robot is "the crown on the top of the manufacturing industry" in the Chinese Academy of Sciences and the Chinese Academy of Engineering. It is the measure of a national scientific and technological innovation and the important sign of high-end manufacturing level. In 2015 World Robot Assembly, Premier Li held a congratulatory and instructions: Robot is not only the important symbol that measures the level of modern technology and high-end manufacturing, but also the strategic field that is the pioneer preempt the opportunities of the development of intelligent society. "Robot revolution" is affecting the global manufacture industry, which will undoubtedly push the development of the robot industry to the consideration of national strategic. From the national sight, the current direction of the robot has become the field of emerging industrial development strategy, which provides opportunities for our undergraduate robot professional training and shows that China is supposed to focus on robot professional training. It requires the creation of industrial robot specialty, and much resource to the undergraduate education in robot specialty around the "Made in China 2025".

Industrial robot is the multi-joint manipulator or multidegree-of-freedom appliance in industrial application, which is able to work automatically. It realizes various functions by its own power and control. The manufacturing industry of China is facing a high-end shift, the undertaking of international advanced manufacturing, participation in the international division of labor. Accelerating the research, development and production of industrial robotic technology is the main means for China to seize this historical opportunity. Establishing industrial robot undergraduate specialty not only provides the professional resources to "Made in China 2025", but also is of practical strategic significance to push the development of robot industry to the national strategy.

\section{MARKET DEMAND AND THE OBJECTIVE OF TALENT TRAINING}

Industrial robot is the most typical electromechanical integrated digital equipment, which integrates mechanical, electronic, control, computer, sensor, artificial intelligence and other disciplines with high added value of technology. With the constant upgrading of enterprises and updating of equipment, the society urges for high-quality professional resource with knowledge and skills of industrial robots. The productivity and competitiveness of enterprises are the decisive factor for Chinese manufacturing enterprises in the global market, and industrial robot is the key to solve this problem. The daily maintenance and repair of the production line of industrial robots require the handling of a large number of professional technicians, which provides a lot of jobs related to robotic specialty virtually.

The industrial robotic employees goes to 4 operating posts, according to their functions, generally speaking:

(1) Senior engineers. They are familiar with programming language and simulation design, as well as artificial neural networks, fuzzy control and other artificial intelligence algorithms. On this basis, they are able to study algorithms 
independently according to the actual situation, and lead largescale electromechanical integration equipment research and development. At the same time, they have management ability that is able to conduct the staffs.

(2) Junior engineers. They are able to adjust the parameter of the robots equipment independently, and do the partial research for the specific robot equipment. In addition, they are supposed to do well in summarizing and communicating with operating staff on site and customers about the installation of equipment, adjustment and maintenance.

(3) Technical workers. They are able to help engineers to design mechanical drawings, electrical drawings, simple fixture, process chart, guide the workers to install through the drawings, debugging and production, and repair the elementary problems and diagnose the faults according to the prompt code of machine faults.

(4) Workers. They are able to operate the equipment normally under the guidance of technical workers, set up program and product according to operating procedures.

For undergraduate students, they are supposed to be competent for being technical workers to achieve the expectation of enterprise after a short-term training. The accumulation of practice and theory for 1-2 years may make them be equal to the junior engineer position that is the backbone force of enterprise. While the outstanding of junior engineers will reach the level of senior engineer after 3-5 years of work and study, as shown in Fig.1. In order to meet the demand of enterprises and transfer qualified professional resources to enterprises, taking the market demand as the guide and formulate reasonable training goal of professional resources are the right things.

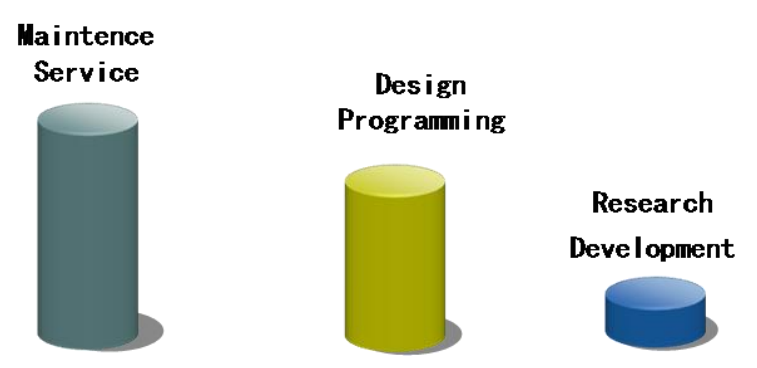

Fig. 1. Industrial robots undergraduate demand

After several years of exploration, the professional undergraduate training goals we have planned are the following: Train the undergraduate students' ability of robotic research and application in college, the undergraduates are supposed to be the applied professions who are engaged in system integration in the direction of the industrial robot, assembling and programming. At the same time, they are able to adapt the applied technology management of industrial robots, installation and commissioning, maintenance, operation of the equipment, customer service etc. According to the training goal, there are 4 directions for the graduates' employment: debugging, programming operation, system integration and maintenance and other technical services, and the robotic research, production, sales and customers' service of industrial robots for the automation production system and industrial robot assembling of large-sized and medium-sized enterprise, the flow chart is shown in Fig.2.

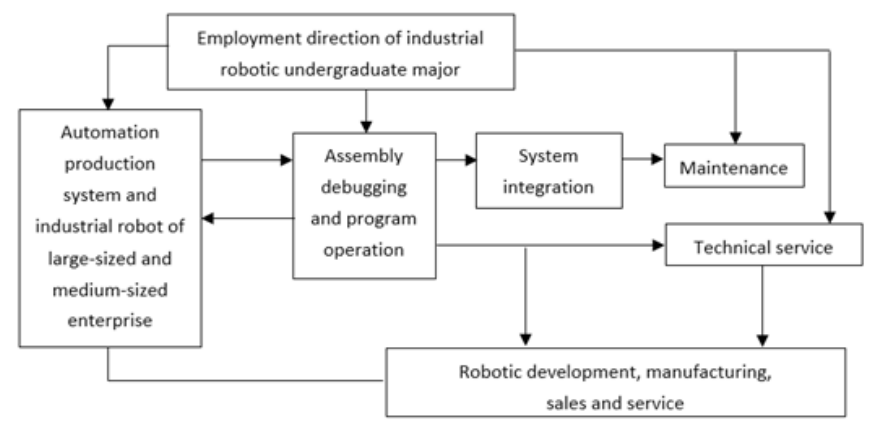

Fig. 2. Employment Direction

\section{CONSTRUCTION OF SPECIALITY COURSES}

Combining the goal of speciality training and employment orientation, adhering to the professional teaching as the center, implementing the project of teaching quality as the main line, reforming teaching contents and curriculum system, optimizing and integrating of curriculum content, strengthening practical teaching, realizing the harmonious development of students' knowledge, ability and quality is the principle of the industrial robotic specialty. Focusing on the direction of professional development closely, we have established a group of highquality teachers with high educational level, reasonable structure in professional title, education and age, being able to adapt to the subject development, high teaching level and strong scientific research ability. By studying the complete teaching quality management and evaluation system, we constantly revise the specialty training program and curriculum syllabus, organize regular teaching inspection activities, supervision, peer assessment and students' evaluation of teaching. By using the means of modern education, the research and teaching activities are promoted, and the training quality of the education is improved. Meanwhile, we strengthen the cross integration with other specialties, so as to enhance the overall competitive strength of this specialty.

At the aspect of the construction of curriculum system, the main task is the basic knowledge teaching of robot in the undergraduate stage, including robot system. At the same time, independent innovation training practice is carried out vigorously in order to cultivate students' observation, analysis, test, design and practical ability. The main courses include: automatic control principle, control theory, flexible manufacturing systems, robotics, robot programming technology, electrical engineering, signal and system, engineering drawing, mechanical design basis, principle and application of single microcomputer, machine vision and artificial intelligence. The architecture of each course is shown in Fig.3. 


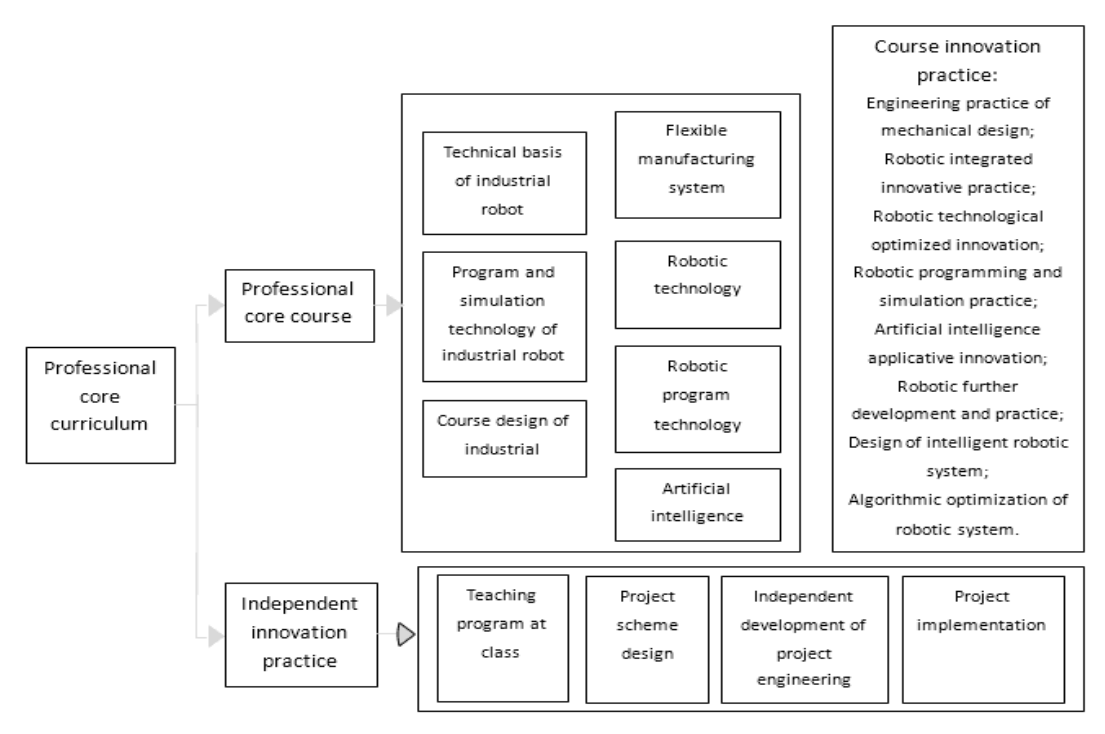

Fig. 3. Professional curriculum system structure

The main knowledge points of the specialty courses are as following:

1) Principle of automatic control (basis of mechanical control engineering). Automatic control is the foundation of robot. In robot motion process, a large number of sensors, calculation and simulation are required to measure and adjust the parameters of the robot, which are used to compensate and feedback according to the calculation result eventually.

2) Artificial intelligence. Various expert systems, machine learning, intelligent computing, heuristic search, distributed artificial intelligence, various intelligent algorithms, such as ant colony algorithm, neural network and so on, are the main points of study.

3) Robotic technology. It explains the mathematical calculations of robotic motion, involving space description, generalized coordinates, transient kinematics, Jacobi matrix explicit (basic linear algebra), stereo vision, trajectory generation, joint space dynamics and Lagrange equation, the cybernetics (as well as auto-control) and the compliance.

4) Robotic programming technology. In order to make the robot move in accordance with the rules, it requires corresponding program. Consequently, being familiar with $\mathrm{C}$ language, assembly language, graphical programming language and so on, are necessary for the graduates.

5) Motor dragging. The motion of a robot is driven by an electric motor, so it is necessary to understand the principle of the motor, the speed regulation, the start and the electromagnetic relationship in the process of robotic design.

\section{COMPREHENSIVE REFORM OF SPECIALTY}

According to the formulated professional training scheme and course system, flexible credit system is adopted for the specialty. In other words, the students are admitted in mechanical engineering. They take courses of mechanical engineering in the first 3 semesters, study and have a general understanding of junior education courses and mechanical basic courses, then they are allowed to choose the industrial specialty or stay in accordance with the provisions of school professional principles and process flow. The basic education system is 4 years, the first 3 semesters are the basic training stage, the latter 5 are professional education stages, and the 3-6 year flexible educational system is adopted.

Centering on specialty construction and personnel training, we integrate school laboratories and related resources of enterprise equipment, reconstruct specialized laboratory systems to solve the problems of insufficient experimental sites and outdated experimental equipment. On the one hand, with the constant development of professional construction and the updating of knowledge structure, laboratory equipment often lag behind some enterprise equipment. On the other hand, enterprises require that the graduates have a certain understanding of the production equipment in their enterprise, in order to make the graduates familiar with the job environment as soon as possible. Making full use of enterprise equipment resources helps to reduce internship training time, and enhances students' practical ability. Therefore, we have established the experimental center of robot teaching. The center consists of three laboratories: robotics basic teaching laboratory, robotics application laboratory and intelligent manufacturing line laboratory, as shown in Fig.4 to Fig.6. 


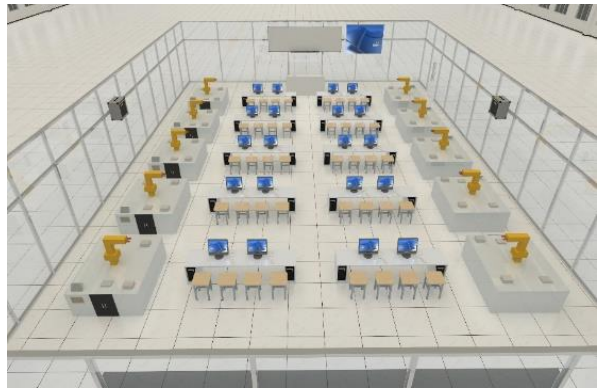

Fig. 4. Robotic basic teaching laboratory

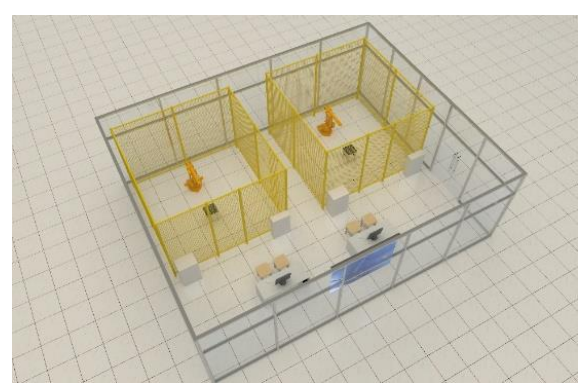

Fig. 5. Robotic Application laboratory

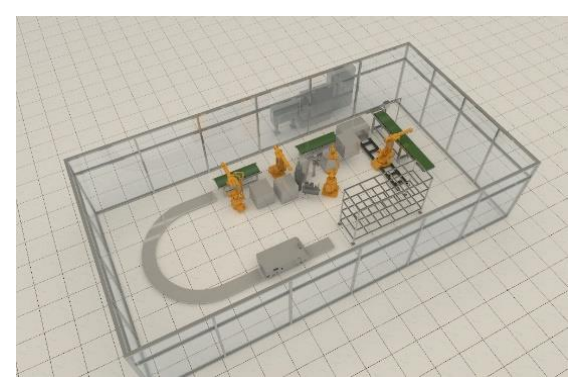

Fig. 6. Intelligent manufacturing line Laboratory

\section{CONCLUSIONS}

According to the "Made in China 2025", it is necessary to cultivate the robotic professionals for the development nowadays. In this paper, the training mode of the original professions is improved, the new curriculum system is built, the deep integration of the robotic technology and traditional mechanical specialty is realized through constructing and reforming the "Industrial robotic specialty", which is positive and significant for the implement of upgrading traditional mechanical specialty and the education of the high-quality talent training with the spirit of innovation and practice ability.

\section{REFERENCES}

[1] WANG Tianmiao, TAO Yong. Research Status and Industrialization Development Strategy of Chinese Industrial Robot. Journal of mechanical engineering, pp.1-5, 2014.

[2] Chen, Xiao Yan, J. Shen, and E. E. Department. Research and Practice of Higher Vocational Industrial Robot Technology Specialty Talent Training Mode. Journal of Jilin Teachers Institute of Engineering \& Technology , 2014.

[3] Niu, Zhi Bin. Construction and Discussion of Industrial Robot Technical Specialty in Higher Vocational Colleges. Vocational Education Research , 2016.

[4] Jiang Sun, Qi Xiao, Manufacturing and innovation ability education of university students majored in mechanical engineering, Applied Mechanics and Materials, vol. 229-231, pp. 2779-2783, 2012.

[5] B.Williams Christopher, Gero John, Lee Yoon, Exploring the effect of design education on the design cognition of Mechanical Engineering students, Proceedings of the ASME Design Engineering Technical Conference, vol. 7, pp. 607-614, 2011.

[6] Shi, Rong. The Practice of Cultivating Innovative Talent Training Mode in the Major of Engineering in High Vocational School by"Internet+" -Taking the Electrical Automation Specialty of Wuxi City College of Vocational Technology as an Example. Computer \& Telecommunication, 2016. 